\title{
Mid-latitude ionospheric perturbation associated with the Spacelab-2 plasma depletion experiment at Millstone Hill
}

\author{
J. C. Foster ${ }^{1}$, J. M. Holt ${ }^{1}$, L. J. Lanzerotti ${ }^{2}$ \\ ${ }^{1}$ Haystack Observatory, Massachusetts Institute of Technology, Westford, MA 01886, USA \\ E-mail: jcf@ haystack.mit.edu \\ ${ }^{2}$ Bell Laboratories, Lucent Technologies, 600 Mountain Ave., Murray Hill, NJ 07974, USA
}

Received: 8 March 1999 / Revised: 1 July 1999 / Accepted: 20 July 1999

\begin{abstract}
Elevation scans across geomagnetic mid latitudes by the incoherent scatter radar at Millstone Hill captured the ionospheric response to the firing of the Space Shuttle Challenger OMS thrusters near the peak of the $F$ layer on July 30, 1985. Details of the excitation of airglow and the formation of an ionospheric hole during this event have been reported in an earlier paper by Mendillo et al.. The depletion (factor $\sim 2$ ) near the $320 \mathrm{~km}$ Shuttle orbital altitude persisted for $\sim 35 \mathrm{~min}$ and then recovered to near normal levels, while at $265 \mathrm{~km}$ the density was reduced by a factor of $\sim 6$; this significant reduction in the bottomside $F$-region density persisted for more than 3 hours. Total electron content in the vicinity of the hole was reduced by more than a factor of 2, and an oscillation of the $F$-region densities with 40-min period ensued and persisted for several hours. Plasma vertical Doppler velocity varied quasiperiodically with a $\sim 80$-min period, while magnetic field variations observed on the field line through the Shuttleburn position exhibited a similar $\sim 80$-min periodicity. An interval of magnetic field variations at hydromagnetic frequencies ( $\sim 95 \mathrm{~s}$ period) accompanied the ionospheric perturbations on this field line. Radar observations revealed a downward phase progression of the 40-min period density enhancements of $-1.12^{\circ} \mathrm{km}^{-1}$, corresponding to a $320-\mathrm{km}$ vertical wavelength. An auroral-latitude geomagnetic disturbance began near the time of the Spacelab-2 experiment and was associated with the imposition of a strong southward IMF Bz across the magnetosphere. This created an additional complication in the interpretation of the active ionospheric experiment. It cannot be determined uniquely whether the ionospheric oscillations, which followed the Spacelab-2 experiment, were related to the active experiment or were the result of a propagating ionospheric disturbance (TID) launched by the enhanced auroral activity. The most reasonable conclusion is that the ionospheric oscillations were a result of the coincident geomagnetic disturbance. The pronounced
\end{abstract}

Correspondence to: J. C. Foster depletion of the bottomside ionosphere, however, accentuated the oscillatory behavior during the interval following the Shuttle OMS burn.

Key words. Ionosphere (active experiments; ionospheric disturbances) - Magnetospheric physics (storms and substorms)

\section{Introduction}

In a sequence of planned experiments, the orbital maneuvering subsystem (OMS) engines of the Space Shuttle Challenger were fired in the vicinity of several radio observatories during the summer of 1985 to obtain data on the ionospheric effects of the exhaust products. The OMS exhaust gases $\left(\mathrm{H}_{2} \mathrm{O}, \mathrm{H}_{2}\right.$, and $\left.\mathrm{CO}_{2}\right)$ react rapidly with the ambient ionospheric plasma, causing the dominant atomic ions $\left(\mathrm{O}^{+}\right)$to be converted to molecular ions which, in turn, recombine rapidly with the ambient electrons to form neutral species. Optical emissions are produced in this process and the end result is to produce a localized depletion of the plasma concentration, an ionospheric hole (Mendillo and Forbes, 1978). The atmospheric modification experiments conducted over the Arecibo Observatory investigated neutral gas dynamics and ion and neutral chemistry effects during supersonic chemical-release experiments and have been reported by Bernhardt et al. $(1988 \mathrm{a}, \mathrm{b})$. The enhancement of radar returns by the Shuttle exhaust plume is discussed by Bernhardt et al. (1995).

Both daytime and nighttime Shuttle exhaust firings and ground-based measurements were successfully performed in the 1985 campaign using the Millstone Hill incoherent scatter radar, optical imaging, and radiopropagation diagnostics. The nighttime experiment on July 30, 1985 used a 47-s OMS burn directly to the south of the Millstone Hill Observatory $\left(42.6^{\circ} \mathrm{N}, 288.5^{\circ} \mathrm{E}, 55^{\circ}\right.$ 
invariant latitude). Some $830 \mathrm{~kg}$ of exhaust products was released near the peak altitude of the ionospheric $F$ layer along a $360-\mathrm{km}$ path of the Shuttle during that interval. The ground-based diagnostic instruments observed airglow emissions and the formation of an ionospheric hole. A description of the Spacelab-2 plasma depletion experiments over Millstone Hill and the characteristics of the resultant ionospheric holes and optical emissions has been reported by Mendillo et al. (1987).

The July 30, 1985, OMS-burn experiment was conducted several hours after sunset, under nighttime conditions, in order to avoid simultaneous re-ionization of the ionosphere. It was planned to produce the largest and most long-lived ionospheric hole that might be produced by the Shuttle (Mendillo et al., 1987). This experiment produced a prompt ionization depletion which spread along the orbital track of the burn and expanded in latitude and altitude to create a hole $\sim 2^{\circ}$ wide, centered at the $41^{\circ} \mathrm{N}$ latitude location of the exhaust deployment. The airglow and the active depletion of the local density subsided over a 20-min interval, but the residual ionospheric hole persisted for $>5 \mathrm{~h}$, until sunrise. In darkness, without the replenishing effects of the solar ionization source, an ionization depletion will persist as a "fossil" after its causative processes have ceased to operate, as will the effects of density gradients or plasma waves associated with its formation. Natural processes, such as transient disturbance-enhanced electric fields (e.g. Schunk et al., 1976), can disturb the normal $F$-layer chemistry resulting in enhanced recombination and the formation of a deep localized density trough at mid-latitudes. Evans et al. (1983) have found such troughs to persist through the night, corotating with the Earth at the longitude at which they were formed. The mid-latitude ionospheric hole generated in the nighttime Spacelab-2 experiment followed such a pattern and persisted through the night. Ionospheric parameters oscillated with $\sim 40$-min and $\sim 80$-min periods through the interval following the initial ionospheric depletion. It cannot be determined uniquely whether the ionospheric oscillations were related to the active experiment or were the result of a propagating ionospheric disturbance (TID) launched by enhanced auroral activity which began nearly simultaneously with the Shuttleburn experiment. In this brief report, we discuss the temporal evolution of the perturbed ionosphere observed by the Millstone Hill radar on the night of July 30,1985 , and its relationship to the auroral disturbance.

\section{Observations}

The Millstone Hill incoherent scatter radar performed a limited elevation scan in the north-south plane, spanning the Shuttle-burn latitude/altitude in order to provide a history and detail of the ionospheric depletion as a function of latitude, altitude, and time. For $\sim 20$ min around the burn time at 03:22 UT (22:22 LT), a fixed beam position was held, intersecting the Shuttle orbit at the midpoint of the burn. The upper panel of Fig. 1 presents contours of averaged plasma density sampled in the $1.5^{\circ}$-wide swath of latitude centered at $41.25^{\circ}$ through the course of the experiment. Data were acquired across this position with approximate 10-min temporal resolution; data in the figure have

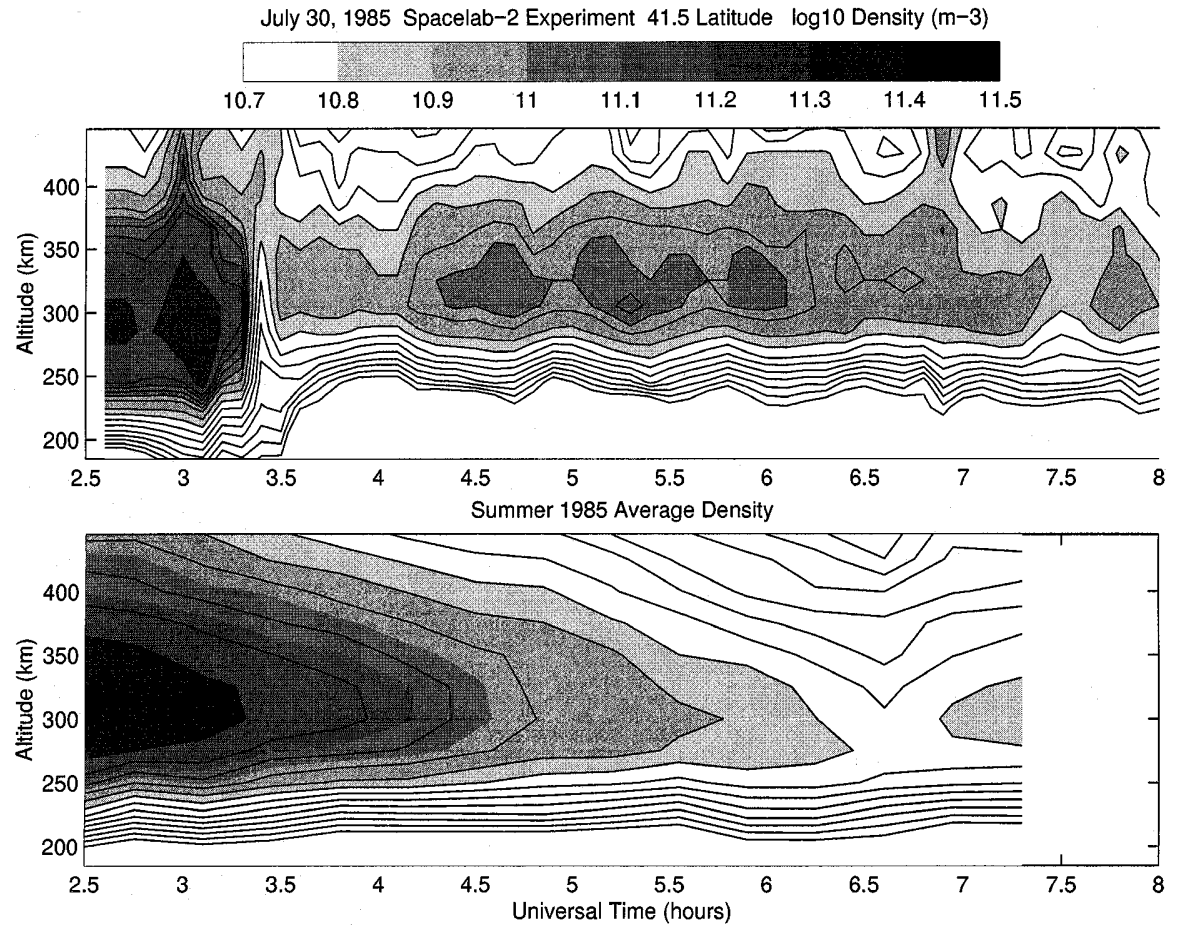

Fig. 1. Iso-density contours observed with the Millstone Hill radar in the $1.5^{\circ}$ latitude swath centered at $41.25^{\circ}$ latitude reveal the perturbation of the mid-latitude ionosphere associated with the Shuttle OMS burn. The lower panel presents the temporal evolution of the unperturbed ionosphere determined as the average of three radar experiments near $42.5^{\circ}$ latitude. Significant depletion and oscillation of the bottomside $F$ layer occurred during the July 30, 1985, experiment 
been bin-averaged across 6 min of UT and $20 \mathrm{~km}$ of altitude, with missing samples interpolated first in altitude and then from adjacent UT bins. In order to accentuate the ionospheric changes following the Shuttle OMS engine burn, the temporal evolution of the unperturbed ionosphere is presented in the lower panel of the figure for comparison with the July 30, 1985, observations. This "normal" ionosphere is derived as the average of the three geomagnetically-quiet Millstone Hill radar experiments which observed the ionospheric profile near $42.5^{\circ}$ latitude within 30 days of the Spacelab-2 experiment.

\subsection{Ionospheric perturbation}

On July 30th, the sharp depletion in density at 03:24 UT produced by the exhaust-induced fast recombination near the Shuttle altitude $(320 \mathrm{~km})$ is apparent, as is a shift in the $F$-layer peak altitude, $h m F 2$, to $\sim 320 \mathrm{~km}$ from the pre-burn peak near $280 \mathrm{~km}$. The bottomside ionization (altitude $<300 \mathrm{~km}$ ) is greatly reduced after the burn and remains depleted through the remainder of the night. The depletion near the $320 \mathrm{~km}$ altitude of the Shuttle orbit persisted for $\sim 40 \mathrm{~min}$ and then recovered to near normal levels. At $265 \mathrm{~km}$, the density was reduced by a factor of $\sim 6$ within $20 \mathrm{~min}$ of the OMS burn, and this significant reduction in the bottomside density persisted for more than $3 \mathrm{~h}$. The mid-latitude ionospheric conductivity, which is directly proportional to electron density and which is significant only at $F$-region heights at night, was reduced by a similar factor. Total electron content (TEC), calculated over the range of altitudes shown in Fig. 1, decreased from 2.5 to 1.0 TEC unit (1 TEC unit $=10^{16} \mathrm{el} \mathrm{m}^{-2}$ ) at the time of the depletion and then remained essentially constant through the remainder of the interval shown in the figure.

The Millstone Hill observations are in contrast to those made during the nighttime Shuttle burn over the Arecibo observatory reported by Bernhardt et al. (1988b). The Arecibo burn was 44 times smaller and produced a 'short-lived' ionospheric hole which diffused along the magnetic field line, sank rapidly downward in altitude, and $\mathbf{E} \times \mathbf{B}$ drifted southward out of the fixed beam of the Arecibo radar within $\sim 5$ min. During the Millstone Hill experiment, the scanning radar antenna was used to monitor a range of latitude and altitude around the initial depletion region, and the ionospheric perturbation was tracked and monitored until sunrise. A quasi-periodic oscillation of the bottomside iso-density contours, with a 40-min period, is seen during the $3-\mathrm{h}$ interval following the burn. Associated variations in TEC were $<10 \%$. The oscillation of the bottomside density is highlighted in Fig. 2 which presents the temporal variation of the density at two altitudes, $300 \mathrm{~km}$ and $260 \mathrm{~km}$. Vertical lines beginning at the time of the Spacelab-2 OMS engine burn (03:22 UT) and repeated with 40-min period highlight the quasi-periodic variation of the density. Plasma Doppler velocity was measured in the radar experiment and this varied quasi-periodically in synchronism with the density variations, but with twice the period $(\sim 80 \mathrm{~min})$, such that a significant velocity variation was associated with every other density oscillation. Doppler velocities at this position are principally in the vertical direction, and this component varied in the range $\pm 40 \mathrm{~m} / \mathrm{s}$ such that the velocity was downward as the iso-density contours decreased in altitude.
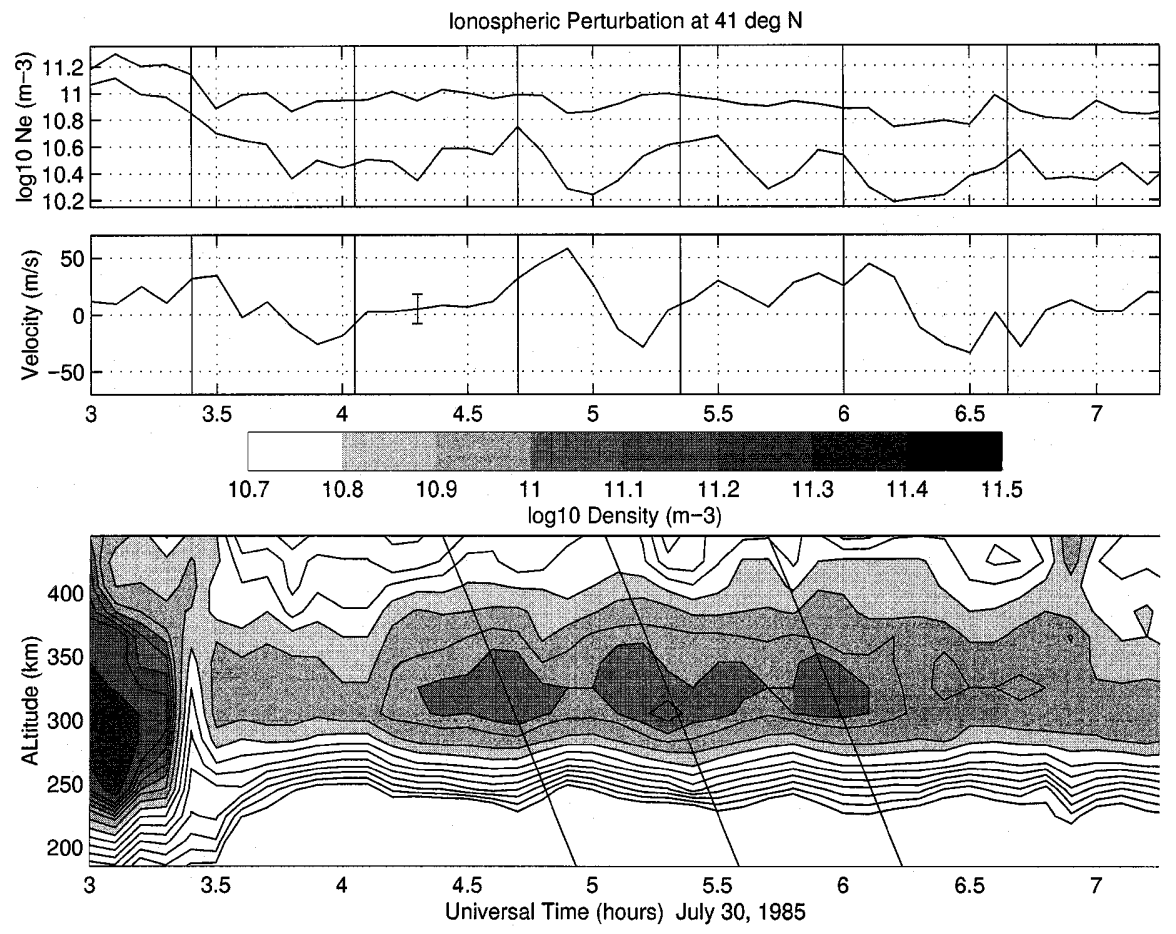

Fig. 2. Temporal variation of the density at two altitudes, $300 \mathrm{~km}$ and $260 \mathrm{~km}$, observed with the radar is shown in the upper panel. Vertical lines beginning at the time of the Spacelab-2 OMS engine burn (03:22 UT) and repeated with 40-min period highlight the quasi-periodic variation of the density at the lower altitude. Velocity data for $41^{\circ}$ latitude and $300 \mathrm{~km}$ altitude are shown in the middle panel. In the lower panel, iso-density contours with overscribed fiducial lines delineate the downward phase progression of the density enhancements. Density peaks were observed to descend $200 \mathrm{~km}$ in altitude in $1460 \mathrm{~s}$ and to repeat with 40 -min period 
The lower panel of Fig. 2 repeats the iso-density contours of Fig. 1 with overscribed fiducial lines to delineate the apparent downward phase progression of the density enhancements. The 40-min separation of the parallel lines indicates a $0.15^{\circ}-\mathrm{s}^{-1}$ phase variation for the density oscillation at a given altitude. The density peak $\left(0^{\circ}\right.$ phase $)$ is observed to descend $200 \mathrm{~km}$ in altitude in $1460 \mathrm{~s}$. Combining these numbers yields a phase variation of $-1.12^{\circ} \mathrm{km}^{-1}$ with altitude, indicating a $320-\mathrm{km}$ vertical wavelength.

The radar antenna was held in a fixed position during the interval around the Shuttle burn at 03:22 UT and elevation scans resumed after 03:36 UT, providing information on the latitude spread and temporal evolution of the ionospheric perturbation. Figure 3 presents plasma density data at fixed altitude $(260 \mathrm{~km})$ in the bottomside $F$ layer. This shows the initial latitude spread of the hole to be $\sim 2^{\circ}$ and the subsequent oscillation of the density over this range of latitude to have an approximate 40 -min period.

\subsection{Perturbation of local magnetic field}

A three-axis fluxgate magnetometer was installed and operated by Bell Laboratories at Greenhill, RI near the footprint of the magnetic flux tube associated with the Shuttle burn. The magnetometer and data recording system acquired measurements in the south-north $(\mathrm{H}$ component), west-east (D), and vertical (Z) directions at two-second intervals. These data for the first $8 \mathrm{~h}$ of that day are shown in Fig. 4A. There is a D-component perturbation with onset at $\sim 03: 31$ UT and continuing in all components until at least 06:30 UT. The magnetic field variations exhibited an $\sim 80$-min periodicity over the interval $\sim 03: 30-06: 00$ UT, similar to that seen in the vertical velocities observed by the radar (see Fig. 2). A negative Z-component perturbation spanned this interval, indicative of an enhancement of the westward ionospheric current poleward of the magnetometer site. The magnetic field signals shown in Fig. 4A were filtered

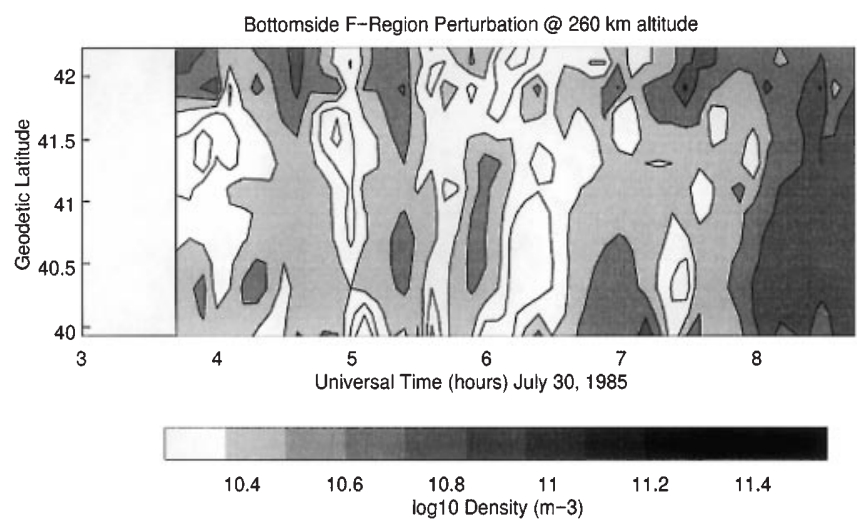

Fig. 3. Radar elevation scan data in the bottomside $F$ layer show the initial latitude spread of the hole to cover $\sim 2^{\circ}$ of latitude and the subsequent oscillation of the density across the field-of-view of the experiment with $\sim 40$-min period. Iso-density contours at fixed altitude $(260 \mathrm{~km})$ are shown in the bands $20-45 \mathrm{~s}, 45-150 \mathrm{~s}$, and $150-300 \mathrm{~s}$. The 20 $45 \mathrm{~s}$ band (not shown) exhibited a brief burst of activity ( $\sim 1.2$ nT peak-to-peak) between $\sim 0326-0338$ UT. However, the filtered variations in the band 45-150 s (Pc4) were much more substantive, as is shown in Fig. 5. Distinct enhancements are evident between $\sim 0326-$ 0405 UT and again $\sim 0420-0500$ UT with a dominant period of $\sim 95 \mathrm{~s}$ and peak-to-peak amplitude of $\sim 1.5$ to $2 \mathrm{nT}$.

\subsection{Magnetospheric disturbance}

A magnetospheric disturbance is the most likely cause of the magnetic perturbations seen in Fig. 4A. The hourlyaveraged AE index (not shown) was closely proportional to the absolute value of the local Z-component magnetic perturbation shown in Fig. 4A, indicating that the local magnetometer provided a good characterization of the variation of the strength of the auroral-latitude currents through this event. The Z-component perturbation spanned the interval 03:30 UT through 07:30 UT and indicates that the disturbance peaked (hourly-averaged $\mathrm{AE} \sim 660 \mathrm{nT}$ ) just prior to $06 \mathrm{UT}$. Coincidentally, the ionospheric oscillations in density and vertical velocity shown in Figs. 1 and 3 occurred only during the interval of geomagnetic disturbance. We have investigated various indicators related to magnetospheric disturbance and intercompare these in the lower panels of Fig. 4. Those data in Fig. 4B-D, and discussed later, indicate that such a geomagnetic disturbance occurred between the hours of 03:30 UT and 07:30 UT on July 30, 1985.

The Kp index on July 30, 1985, (not shown) was basically steady in the range 2 to 3 for the first $9 \mathrm{~h}$ of the day, indicating that a major global disturbance did not occur. Solar wind data from the IMP-8 spacecraft (GSM coordinates, $[-25,-17,22], \mathrm{Re}$ ), shown in Fig. 4B, indicate that the north-south component of the interplanetary magnetic field IMF Bz turned negative near 02:00 UT, followed by an increase in solarwind number density and a brief (30-min) rotation of the magnetic field, near 03:00 UT. Beginning at 03:20 UT, $\mathrm{Bz}$ turned southward and remained strongly negative $(-8 \mathrm{nT})$ through the interval 03:30-06:00 UT.

Southward-directed IMF results in energization of the magnetosphere and most often leads to substorm disturbance, with the mean time between the Bz southward turning and the onset of the substorm expansion phase observed to be $\sim 80$ min (Foster et al., 1971).

Satellite observations are used to characterize the extent and magnitude of the ensuing auroral disturbance. The zero-energy electron boundary determined from DMSP satellite measurements (Newell et al., 1996) is shown in Fig. 4C. This boundary serves to locate the equatorward extent of the auroral convection electric field, and often the plasmapause, since the earthward extent of zero-energy particles is determined solely by $\mathbf{E} \times \mathbf{B}$ drifts (Newell et al., 1996). This boundary moves equatorward between about 03:30 UT and 07:00 UT, with temporal characteristics similar to the 

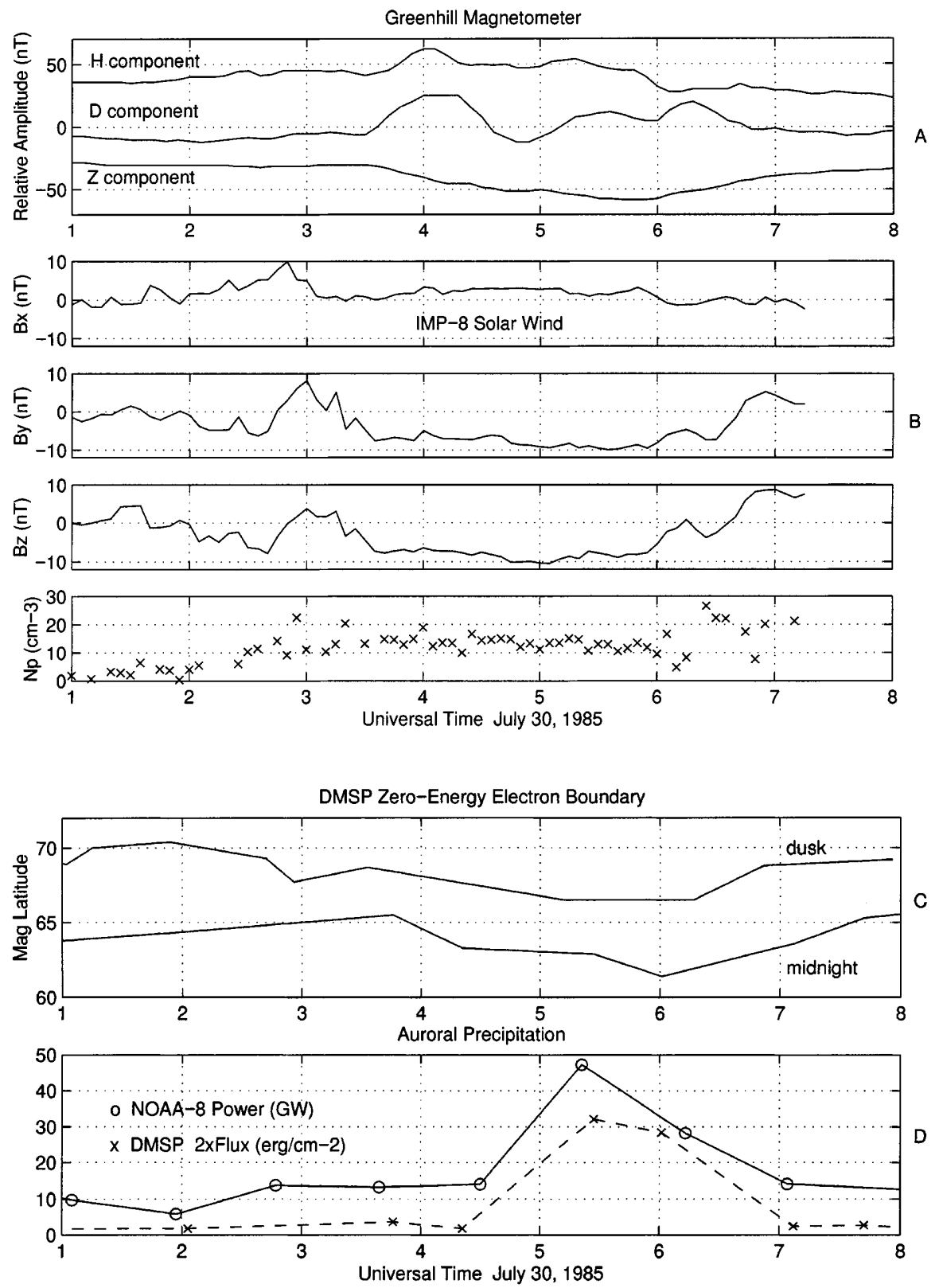

Fig. 4. A Magnetic field variations observed by the Bell Labs magnetometer located on the field line intersecting the Spacelab-2 OMS burn. A pronounced D-component oscillation with 80-min period began at 03:31 UT. A negative $Z$ perturbation spanned the interval 03:30 07:00 UT. B Interplanetary magnetic field and plasma parameters observed by IMP-8 indicate a southward turning of IMF Bz and increase in solar wind plasma density in the interval following 03:00 UT on July 30, 1985. Such conditions could lead to enhanced magnetospheric activity. C DMSP zero-energy electron boundary (Newell et al., 1996) moved equatorward between 03:30 UT and 07:00 UT, indicative of an equatorward expansion of the extent of auroral electric fields. D NOAA-8 precipitating power estimates and DMSP centralplasmasheet flux indicate an increase in auroral-latitude precipitation between 05:00 UT and 06:00 UT
Z-component magnetic deflection seen in Fig. 4A. This suggests that the electrojet current poleward of the Greenhill magnetometer site intensified, and perhaps moved equatorward, during this interval. The hemispheric auroral precipitation energy input derived from NOAA-8 overflights of auroral latitudes (Foster et al., 1986, Fuller-Rowell and Evans, 1987) is presented in Fig. 4D, together with the midnight-sector averaged electron precipitation flux determined in the centralauroral region from the DMSP data (following Newell et al., 1996). Both these measures of auroral particle loss indicate that strong precipitation occurred between 05 06 UT (near magnetic midnight on the US east coast), considerably after the Shuttle OMS burn and the onset of the ionospheric and magnetometer oscillations. These monitors do not provide evidence of an enhancement in auroral precipitation near the time of onset of the ionospheric variations ( $\sim 330$ UT) shown in Fig. 1.

\section{Discussion}

There are three potential explanations for the pronounced ionospheric oscillations observed in the vicinity of Millstone Hill on July 30, 1985. The observations reported could have been (1) persistent effects of the artificial ionospheric perturbation and a direct result of the Shuttle thruster burn, or (2) effects associated with the nearly-coincident substorm occurrence and unrelated to the active experiment, or (3) indicative of a coupling between the Shuttle-produced ionospheric perturbation and the characteristics of the ensuing substorm.

Attributing the ionospheric oscillations to a TID associated with the substorm is the most logical and easily defensible conclusion, but the unusual characteristics of the ionospheric effects and the close coincidence of the substorm onset to the initial ionospheric perturbation produced by the Shuttle burn, prompt us to 


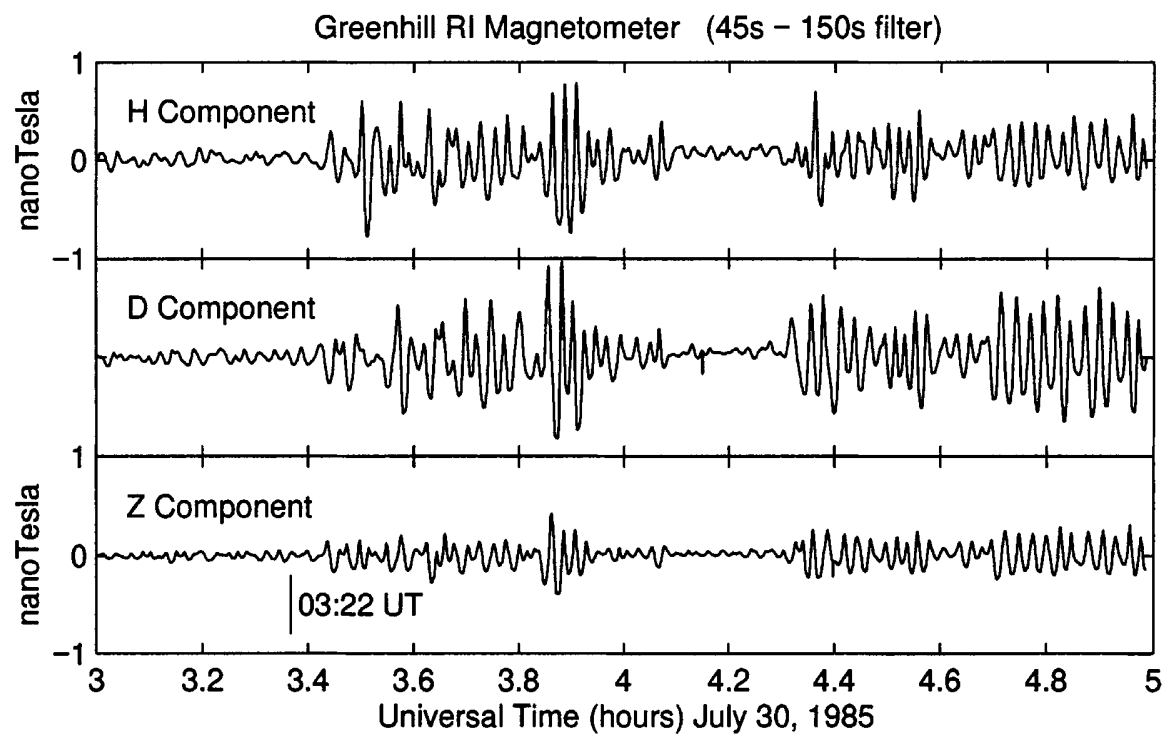

Fig. 5. Magnetic field signals filtered in the $45 \mathrm{~s}-150 \mathrm{~s}$ band show bursts of pulsation activity following the Shuttle-burn experiment at 03:22 UT. The onset of pulsation activity occurred at $\sim 03: 26$ UT include some additional information related to each of these three possible scenarios.

\subsection{Persistent effects of artificial ionospheric perturbation}

The Spacelab-2 experiments were not the first to investigate the effects of discrete ionospheric perturbations. Mendillo et al. (1975) present beacon-satellite observations of TEC in the vicinity of the trajectory of the Skylab launch while Wand and Mendillo (1984) report Millstone Hill radar observations of the ionospheric effects of the launch of HEAO-C. Neither of these daytime studies observed any persistent oscillations of the ionosphere following the creation of large-scale ionospheric holes by the launch-vehicle exhaust products at $F$-region heights. Arendt $(1971,1972)$ reported ionospheric undulations observed with remote ionosondes during the launches of Apollo 14 and Apollo 15. He interpreted these in terms of the sequential arrival of single-pulse ion acoustic and neutral acoustic waves generated when a large launch vehicle and its exhaust plume travel with supersonic velocity through the ionosphere. Chimonas and Hines (1970) had predicted the generation of such remote ionospheric disturbances by the passage of a supersonic shock through the atmosphere. The ion acoustic wave disturbances associated with the Apollo launches were observed at all heights in the bottomside $F$ layer and were determined to propagate at an average speed of $1.4 \mathrm{~km} \mathrm{~s}^{-1}$ over the $\sim 1000 \mathrm{~km}$ distance to the observing point. In the case of the Spacelab-2 OMS-thruster burn, the exhaust gases entered the background ionosphere with a supersonic relative velocity of $\sim 5 \mathrm{~km} \mathrm{~s}^{-1}$ in the direction of the Shuttle's motion (Mendillo et al., 1987), conditions appropriate for the initiation of a propagating ionospheric disturbance. These previous studies indicate that the Shuttle burn could have initiated a propagating ionospheric disturbance, but do not account for the persistent ionospheric oscillation observed during the event.
Rosenberg et al. (1981) reported observations of the excitation of Alfvén waves in the Earth's magnetosphere following sudden changes in the ionospheric conductivity. In that study, the sudden increase in $D$ and $E$ region conductivity produced by solar-flare X-ray and ultraviolet fluxes was observed to produce magnetic field variations in the $\sim 0.01 \mathrm{~Hz}$ band. Those authors postulated that the sudden conductivity change would lead to an impulsive change in the horizontal current flow and, thence, to a transverse magnetic perturbation sufficient to excite resonance oscillations of the field line. For field lines near $L=4$, the eigenmodes of the fundamental oscillations are in the 45-150 s (Pc4) and 15-45 s (Pc3) frequency bands for field lines inside or outside the plasmapause, respectively. Rosenberg et al. (1981) speculated that the excitation of hydromagnetic field-line resonance might also be expected to accompany a rapid decrease of ionospheric conductivity such as could be produced by chemical releases in the ionosphere. The Greenhill magnetometer observations on July 30, 1985, were made to determine what magnetic field effects, if any, could be attributed to the active ionospheric experiment. Our observations of the magnetic field perturbation along the magnetic field line through the Shuttle burn indicated that the filtered variations in the band 45-150 s (Pc4) were strongest, with distinct enhancements evident between $\sim 0326-0405$ UT and again 0420-0500 UT. Although these observations are in keeping with the Rosenberg et al. (1981) prediction, they are more easily explained as being related to the substorm onset.

\subsection{Magnetic storm/substorm effects}

The interpretation of the mid-latitude ionospheric perturbations which accompanied the Spacelab-2 active experiment at 03:22 UT is complicated by the competing effects of the auroral-latitude disturbance which began at nearly the same time. Energy deposition at high 
latitudes during a magnetospheric disturbance can launch a traveling ionospheric disturbance (TID) (e.g. Harper, 1972; Roble et al., 1978) which could be responsible for the long-period ionospheric variations observed by the radar in the Spacelab-2 experiment. Most reports of TIDs involve strong disturbances and the appearance of a single propagating ionospheric pulse (e.g., Bowman, 1965; Roble et al., 1978). The Arecibo radar observations of a storm-induced TID reported by Harper (1972) describe several cycles of ionospheric oscillation with a 105-min period, including an oscillation of the vertical velocities with $\sim 50 \mathrm{~m} / \mathrm{s}$ amplitude. These Arecibo observations are quite similar to those we report here, with the important exceptions of the magnitude of the causative disturbance and the relative timing of the onset of the ionospheric oscillations. Harper's (1972) event occurred on 7 November, 1970, and followed a storm sudden commencement in which $K p$ increased from $2^{+}$to $6^{0}, A E$ from $200 \mathrm{nT}$ to $1000 \mathrm{nT}$, and with $D s t<-100 \mathrm{nT}$. Those Arecibo oscillations followed this impulsive increase in activity by $\sim 2 \mathrm{~h}$. The considerably weaker substorm disturbance which accompanied the Millstone Hill oscillations involved an increase in $K p$ from $2^{-}$to $3^{0}, A E$ from $80 \mathrm{nT}$ to $180 \mathrm{nT}$, and produced no perturbation in Dst. (The disturbance further intensified to $A E>500 \mathrm{nT}$ during the second hour following the onset of the Millstone Hill oscillations.) Although the associated auroral disturbance was weak, the similarity of our observations to those of Harper (1972), suggests that the ionospheric oscillations observed over Millstone Hill during the Shuttle-burn experiment were the result of a propagating ionospheric disturbance (TID) launched by the nearly simultaneous onset of enhanced auroral activity.

If this is the case, some features of the TID propagation characteristics can be derived from the Millstone Hill radar observations. The positive bottomside $F$-region perturbation which appears near $42^{\circ}$ geographic latitude $\left(54^{\circ} \Lambda\right)$ at $\sim 0430$ UT (see Fig. 3) exhibits an apparent equatorward motion of $\sim 300 \mathrm{~m} \mathrm{~s}^{-1}$. If this were a signature of a TID with a source at auroral latitudes (nominally $65^{\circ} \Lambda$ ), and propagating equatorward at constant speed, a source time of $\sim 0330$ UT is determined. This is consistent with our estimates of the onset of the magnetospheric (substorm) disturbance discussed already.

The magnetic variations following the Shuttle burn reported, occurred in approximate time coincidence with the southward turning of the IMF, and the likelihood that a geomagnetic substorm was initiated thereafter. Indeed, the magnetic pulsation frequencies shown in Fig. 5 are consistent with those associated with Pi2 pulsations, which are known to be in approximate time coincidence with substorm onsets (e.g. Rostoker, 1968). If the initial magnetic variations observed in the $45 \mathrm{~s}-$ $150 \mathrm{~s}$ band are a burst of Pi2 pulsations associated with substorm onset, then these data indicate that the substorm began at $\sim 03: 26 \mathrm{UT}$, some $4 \mathrm{~min}$ after the firing of the Shuttle thrusters and the perturbation of the mid-latitude, pre-midnight $F$-region conductivity. Hence, given the near coincidence of the Shuttle burn with the southward turning of the IMF, it would be very difficult to argue convincingly for the Shuttle initiation of the magnetic variations through the mechanism suggested by Rosenberg et al. (1981).

\subsection{Magnetosphere-ionosphere interaction}

The observations reported here indicate that the interval of long-period $(40 \mathrm{~m}$ and $80 \mathrm{~m}$ ) ionospheric and magnetic oscillations, and the onset of substorm activity and of $\sim 95$ s period magnetic pulsations, occurred promptly after the formation of the ionospheric hole. It is possible, though speculative, that the ionospheric disturbances set up as the Shuttle exhaust gases interacted with the mid-latitude ionosphere on July 30, 1985, coupled into the overlying magnetosphere and affected the growing IMF-induced magnetospheric disturbance.

The stimulation of hydromagnetic waves in the Pc4 band is consistent with the theoretically predicted range of (80 s-100 s) for an $L \approx 3$ field line located inside the plasmapause (Orr and Matthew, 1971). Although $D$ and $E$-region conductivities were not measured during the experiment, and are not believed to have been affected directly by the Shuttle-exhaust recombination, the conductivity of the nighttime mid-latitude ionosphere is dominated by the density in the lower $F$ region, and this was reduced by a factor of $\sim 4$ during the formation of the ionospheric hole. This rapid depletion of the lower $F$-region density, and the proportional conductivity decrease, could have provided an impulsive perturbation of the mid-latitude current, as discussed by Rosenberg et al. (1981). The lower $F$-region perturbation occurred in time coincidence with the onset of the magnetic variations and could therefore be responsible for exciting the waves. In this scenario, the effects of the localized ionospheric perturbation produced by the Shuttle burn could be coupled into the overlying magnetosphere by varying the conductance at the ionospheric foot of the field line. Such ionosphere-magnetosphere coupling could then bring into play the wide range of magnetospheric processes, which could amplify or spread the effects of the initial perturbation through the coupled magnetosphere-ionosphere system.

The following studies indicate that localized ionospheric perturbations do couple into the overlying magnetosphere, where their effects can be spread more rapidly than through normal ionospheric propagation paths. Coupling of ionospheric perturbations into the magnetosphere has been suggested to explain the prompt arrival of ionospheric perturbations over large distances following discrete natural and artificial disturbances. Taran et al. (1985) report an event in which a fast-propagating ionospheric disturbance was observed with the Kharkov incoherent scatter radar as well as at distributed ionosonde and Doppler radar sites across the Soviet Union in response to a large surface explosion ( $\sim 300$ tons TNT). Propagation speed for the direct arrival of the ionospheric disturbances at various sites was determined to be in the range $2 \mathrm{~km} \mathrm{~s}-10 \mathrm{~km} \mathrm{~s}$. 
Sochatsky et al. (unpublished manuscript, 1990) have used powerful military radars to investigate ionospheric disturbances accompanying missile launches. They report the occurrence of quick ionospheric disturbances observed at distances of $1000 \mathrm{~km}$ to $10000 \mathrm{~km}$ which they attribute to hydromagnetic waves propagating along magnetospheric paths and resulting in apparent ionospheric propagation speeds of between $1 \mathrm{~km} \mathrm{~s}$ and $10 \mathrm{~km} \mathrm{~s}$. A variety of radio techniques have been used by Chernogor et al. (1993) to investigate ionospheric characteristics and their response to discrete perturbations. They report a category of events which exhibit apparent ionospheric propagation speeds of $10 \mathrm{~km} \mathrm{~s}-$ $30 \mathrm{~km} \mathrm{~s}$. Such propagation speeds vastly exceed the limits of ionospheric acoustic propagation and these reports suggest that there are mechanisms which couple a localized ionospheric perturbation into the magnetosphere, where its effects can propagate at the Alfvén speed to produce observable ionospheric signatures on field lines far distant from the causative event. A corollary to these studies of fast trans-ionospheric propagation is that the causative ionospheric perturbations can penetrate the magnetosphere, where their effects might modify magnetospheric processes. The extent to which the ionospheric changes produced by the July 31, 1985, Shuttle burn coupled into the magnetosphere is unknown, but the synchronism of ionospheric and magnetospheric effects during the event suggests that further investigations into the workings of magnetosphere-ionosphere coupling and feedback are needed.

\section{Conclusions}

The auroral-latitude geomagnetic disturbance, associated with the southward turning of the IMF, and which began in near time-coincidence with the Spacelab-2 experiment, presents a serious complication in the interpretation of the Spacelab-2 active ionospheric experiment. As intended, the Shuttle-burn experiment produced a long-lived depletion of the bottomside $F$-layer ionization which persisted for $>5 \mathrm{~h}$, until sunrise. Four complete cycles of ionospheric density oscillations with $\sim 40$-min period were observed following with the Shuttle-produced depletion. It cannot be determined conclusively whether the ionospheric oscillations were related to the active experiment or were the result of a propagating ionospheric disturbance (TID) launched by the nearly simultaneous onset of enhanced auroral activity. The most reasonable conclusion is that the ionospheric oscillations were a result of the coincident geomagnetic disturbance. In that case, the strong ionospheric perturbations associated with the substorm effectively masked any further ionospheric variations directly attributable to the active experiment.

Acknowledgements. Special thanks are due to M. Mendillo who was Principal Investigator of the Spacelab-2 plasma depletion experiment and who provided useful comments on the contents of this study. NOAA- 8 hemispheric power input data were provided by D. Evans and the DMSP electron-boundary and precipitating flux data (P. Newell) and the IMP-8 solar wind and IMF data
(C. Russell) have been made available electronically by the instrument investigators. Helpful discussions with T. Rosenberg, M. Buonsanto, and members of the Atmospheric Sciences Group at the MIT Haystack Observatory are gratefully acknowledged. Millstone Hill observations and analysis are supported by the National Science Foundation through a co-operative agreement with the Massachusetts Institute of Technology.

The Editor-in-chief thanks P.A. Bernhardt and T. Rosenberg for their help in evaluating this paper.

\section{References}

Arendt, P. R., Ionospheric undulations following Apollo 14 launching, Nature, 231, 438, 1971.

Arendt, P. R., Ionospheric shock front from Apollo 15 launching, Nature Phys. Sci., 236, 8, 1972.

Bernhardt, P. A., G. Ganguli, M. C. Kelley, and W. E. Swartz, Enhanced radar backscatter from space shuttle exhaust in the ionosphere, J. Geophys. Res., 100, 23 811, 1995.

Bernhardt, P. A., B. A. Kashiwa, C. A. Tepley, and S. T. Noble, Spacelab 2 upper atmospheric modification experiment over Arecibo, 1, neutral gas dynamics, Astrophys. Lett. Comm., 7, 169, 1988a.

Bernhardt, P. A., W. E. Swartz, M. C. Kelley, M. P. Sulzer, and S. T. Noble, Spacelab 2 upper atmospheric modification experiment over Arecibo, 2, plasma dynamics, Astrophys. Lett. Comm., 7, 183, 1988b.

Bowman, C. G., Traveling disturbances associated with ionospheric storms, J. Atmos. Terr. Phys., 27, 1247, 1965.

Chernogor, L. F., K. P. Garmash, S. G. Leus, O. V. Pakhomova, S. N. Pokhil'ko, and Y. Y. Sorokolet, Experimental investigations of variations of characteristics of radio signals and radio noise in different ranges, conditioned by disturbances in the ionosphere, Proc. Phys. in Ukraine 1993, p 58, Bogolyubov Inst. for Theoretical Physics, Kiev, Ukraine, 1993.

Chimonas, G., and C. O. Hines, Atmospheric gravity wave induced by a solar eclipse, J. Geophys. Res., 75, 875, 1970.

Evans, J. V., J. M. Holt, W. L. Oliver, and R. H. Wand, The fossil theory of nighttime high latitude $F$ region troughs, J. Geophys. Res., 88, 151, 1978.

Foster, J. C., D. H. Fairfield, K. W. Ogilvie and T. J. Rosenberg, Relationship of interplanetary parameters and occurrence of magnetospheric substorms, J. Geophys. Res., 76, 6971, 1971.

Foster, J. C., J. M. Holt, R. E. Musgrove, and D. S. Evans, Ionospheric convection associated with discrete levels of particle precipitation, Geophys. Res. Lett., 13, 656, 1986.

Fuller-Rowell, T. J., and D. S. Evans, Height-integrated Pedersen and Hall conductivity patterns inferred from the NOAATIROS satellite data, J. Geophys. Res., 92, 7606, 1987.

Harper, R. M., Observation of a large nighttime gravity wave at Arecibo, J. Geophys. Res., 77, 1311, 1972.

Mendillo, M., and J. M. Forbes, Artificially created holes in the ionosphere, J. Geophys. Res., 83, 5785, 1978.

Mendillo, M., G. S. Hawkins, and J. A. Klobuchar, A sudden vanishing of the ionospheric $\mathrm{F}$ region due to the launch of Skylab, J. Geophys. Res., 80, 2217, 1975.

Mendillo, M., J. Baumgardner, D. P. Allen, J. Foster, J. Holt, G. R. A. Ellis, A. Klekociuk, and G. Reber, Spacelab-2 plasma depletion experiments for ionospheric and radio astronomical studies, Science, 238, 1260, 1987.

Newell, P. T., Y. I. Feldstein, Y. I. Galperin, and C.-I. Meng, Morphology of nightside precipitation, J. Geophys. Res., 101, $10737,1996$.

Orr, D., and J. A. D. Matthew, The variation of geomagnetic micropulsation periods with latitude and the plasmapause, Planet. Sp. Sci., 19, 2897, 1971.

Roble, R. G., A. D. Richmond, W. L. Oliver, and R. M. Harper, Ionospheric effects of the gravity wave launched by the September 18, 1974 sudden commencement, J. Geophys. Res., 83, 999, 1978. 
Rosenberg, T. J., P. B. Morris, and L. J. Lanzerotti, Excitation of magnetospheric hydromagnetic waves by solar-flare-induced change in ionospheric conductivity, Phys. Rev. Lett., 47, 1343, 1981.

Rostoker, G., Macrostructure of geomagnetic bays, J. Geophys. Res., 73, 4217, 1968.

Schunk, R. W., P. M. Banks, and W. J. Raitt, Effects of electric fields and other processes upon the nighttime high-latitude $F$ layer, J. Geophys. Res., 80, 3121, 1976.
Taran, V. I., Ya. I. Pod'yachiy, A. N. Smirnov, L. Yc. Gershtain, Incoherent scatter radar observations of the ionospheric disturbances after powerful explosion (in Russian), Izv. $A N$ USSR, Physica Zemli, 11, 75, 1985.

Wand, R. H., and M. Mendillo, Incoherent scatter observations of an artificially modified ionosphere, J. Geophys. Res., 89, 203, 1984. 